ARTICLE

\title{
Young asteroidal fluid activity revealed by absolute age from apatite in carbonaceous chondrite
}

\author{
Ai-Cheng Zhang ${ }^{1,2}$, Qiu-Li Li ${ }^{3}$, Hisayoshi Yurimoto 2,4 , Naoya Sakamoto ${ }^{4}$, Xian-Hua Li ${ }^{3}$, Sen Hu ${ }^{5}$, Yang-Ting Lin ${ }^{5}$ \\ \& Ru-Cheng Wang ${ }^{1}$
}

Chondritic meteorites, consisting of the materials that have formed in the early solar system (ESS), have been affected by late thermal events and fluid activity to various degrees. Determining the timing of fluid activity in ESS is of fundamental importance for understanding the nature, formation, evolution and significance of fluid activity in ESS. Previous investigations have determined the relative ages of fluid activity with short-lived isotope systematics. Here we report an absolute ${ }^{207} \mathrm{~Pb} /{ }^{206} \mathrm{~Pb}$ isochron age $(4,450 \pm 50 \mathrm{Ma})$ of apatite from Dar al Gani (DaG) 978, a type 3.5, ungrouped carbonaceous chondrite. The petrographic, mineralogical and geochemical features suggest that the apatite in $\mathrm{DaG} 978$ should have formed during metamorphism in the presence of a fluid. Therefore, the apatite age represents an absolute age for fluid activity in an asteroidal setting. An impact event could have provided the heat to activate this young fluid activity in ESS.

\footnotetext{
${ }^{1}$ State Key Laboratory for Mineral Deposits Research, School of Earth Sciences and Engineering, Nanjing University, Nanjing 210046, China. ${ }^{2}$ Department of Natural History Sciences, Hokkaido University, Sapporo 060-0810, Japan. ${ }^{3}$ State Key Laboratory of Lithospheric Evolution, Institute of Geology and Geophysics, Chinese Academy of Sciences, Beijing 100029, China. ${ }^{4}$ Isotope Imaging Laboratory, Creative Research Institution Sousei, Hokkaido University, Sapporo 001-0021, Japan. ${ }^{5}$ Key Laboratory of Earth and Planetary Physics, Institute of Geology and Geophysics, Chinese Academy of Sciences, Beijing 100029, China. Correspondence and requests for materials should be addressed to A.C.Z. (email: aczhang@nju.edu.cn).
} 
C hondritic meteorites (chondrites) are composed of the solid minerals that have formed in the early solar system (ESS). They are the most precious samples to constrain primary processes that have been prevailed in the solar nebula ${ }^{1,2}$. However, most of the chondritic meteorites have been affected by later fluid activity to various extents ${ }^{3-5}$. Fluid activity has changed the mineralogy, chemistry and isotope compositions of chondrites through fluid-mineral interactions (that is, aqueous alteration, metasomatism and fluid-assisted metamorphism ${ }^{6}$ ). Constraining when and where these fluidmineral interaction events took place is important to understand the thermal histories of chondrite parent bodies and the temporal-spatial evolution of fluids in the solar nebular and asteroidal settings ${ }^{7}$. The formation time of secondary minerals can further constrain the heating sources that have driven the fluid-mineral interaction events in ESS (for example, decay of ${ }^{26} \mathrm{Al}$, heating during accretion of chondritic components to form asteroidal parent bodies and impact heating). Previous investigations have dated a few secondary minerals (for example, carbonate minerals, ferroan olivine, magnetite, nepheline and grossular) that have formed by low-temperature and metamorphic processes in the presence of fluids, based on short-lived isotopic systematics (for example, ${ }^{53} \mathrm{Mn}-{ }^{53} \mathrm{Cr}$, ${ }^{129} \mathrm{I}-{ }^{129} \mathrm{Xe}$ and ${ }^{26} \mathrm{Al}-{ }^{26} \mathrm{Mg}$ systematics ${ }^{7}$ ). Most of these studies revealed that fluid activity in ESS has started within 1-2 Myr after the formation of Allende Ca,Al-rich inclusions (CAIs) and lasted up to $15 \mathrm{Myr}$ (refs 5,7). A few studies, however, found no resolvable excess of daughter nuclides ${ }^{8}$, indicating an extended period of fluid activity ( $>25 \mathrm{Myr}$ ). However, no absolute ages have been reported for constraining fluid activities in ESS up to date. It also remains unknown how late fluid activities could be present in ESS and whether fluid activity is coupled with young metamorphic processes. This is partly due to the fact that dating using short-lived isotope systems is only applicable to events that occurred several to tens of millions after the solar system formation. In addition, to date, most of the secondary minerals (for example, phyllosilicate, carbonate and magnetite) in chondritic meteorites are not suitable for long-lived isotope geochronology.

Apatite is an important volatile-rich mineral $\mathrm{Ca}_{5}\left(\mathrm{PO}_{4}\right)_{3}(\mathrm{~F}, \mathrm{Cl}, \mathrm{OH})$ in chondrites. Apatite and merrillite $\left[\mathrm{Ca}_{9} \mathrm{NaMg}\left(\mathrm{PO}_{4}\right)_{7}\right]$ in chondrites are thought to be secondary minerals, due to the large difference in condensation temperatures for $\mathrm{Ca}$ and $\mathrm{P}$ (refs 9,10). This is consistent with the absence of $\mathrm{Ca}$-phosphate minerals in most primitive chondrites $^{1}$. The formation of apatite in chondrites is usually attributed to fluid activity $5,9,11,12$, although their formation conditions may vary in different chondrites of various petrologic types (from type 1 to type 6). With the developments of uranium-lead (U-Pb) geochronology with secondary ion mass spectrometer (SIMS), apatite can be dated with detailed petrographic context in polished thin sections ${ }^{13-15}$. Therefore, combined with petrographic and geochemical observations, the age of apatite in chondrites can constrain the absolute ages of fluid activity in ESS and/or subsequent heating events (for example, refs 16,17).

$\mathrm{DaG} 978$ is an ungrouped and low petrologic type $(\sim 3.5)$ carbonaceous chondrite with a low abundance of volatile elements ${ }^{18}$. It contains many relatively coarse chlorapatite grains (up to $280 \mu \mathrm{m}$ in size ${ }^{19}$ ). Here we report on the petrography, mineralogy, rare earth elements (REEs) and oxygen isotopic compositions, and $\mathrm{U}-\mathrm{Pb}$ isotopic systematics of the apatite in $\mathrm{DaG}$ 978. Our data reveal that the apatite in DaG 978 could have formed during a metamorphic event in the presence of fluid. Its age represents the first absolute age of fluid activity in ESS.

\section{Results}

General petrography and mineralogy of DaG 978. The detailed petrography and mineralogy of $\mathrm{DaG} 978$ have been reported in ref. 19. The most important features indicative of secondary processes are briefly described here. DaG 978 contains well-defined chondrules, refractory inclusions and fine-grained matrix (mainly, olivine, pyroxene and plagioclase). However, most of the olivine grains in chondrules and refractory inclusions from DaG 978 are $\mathrm{Fe}$ rich $(\mathrm{Mg} \#[\equiv 100 \times \mathrm{Mg} /(\mathrm{Mg}+\mathrm{Fe})]=65-76)$, whereas their associated low-Ca pyroxene grains in chondrules are $\mathrm{Fe}$ poor $(\mathrm{Mg} \#=93-99)$. Most of the Fe-rich olivine grains in type IIA chondrules from $\mathrm{DaG} 978$ have low $\mathrm{Cr}_{2} \mathrm{O}_{3}$ contents ( $\left.<0.2 \mathrm{wt} \%\right)$. A maximum metamorphic temperature of $\sim 580-680^{\circ} \mathrm{C}$ was deduced, based on the compositions of coexisting spinel and olivine ${ }^{19}$. Kamacite and taenite contain $3.8-7.4 \mathrm{wt} \%$ and 34.2-44.6 wt\% $\mathrm{Ni}$, respectively. Many of the CAIs in DaG 978 contain fine-grained troilite (Supplementary Fig. 1). Lath-shaped olivine grains replacing low-Ca pyroxene occur in some ferromagnesian chondrules and chondrule fragments. Nepheline grains are present as inclusions in some of these lath-shaped olivine grains and as lamellae in anorthite grains. Apatite is common in DaG 978 and has a wide occurrence (described below).

Petrography and mineralogy of apatite and merrillite. Coarse-grained apatite ( $>20 \mu \mathrm{m}$ in size) has three major textural occurrences in DaG 978 (Fig. 1). First, the majority of apatite grains in DaG 978 are closely associated with altered CAIs that can contain secondary minerals such as nepheline, Na-rich plagioclase and troilite (Fig. 1a; Supplementary Fig. 1). Most of the apatite grains associated with altered CAIs are subhedral-euhedral in shape with well-developed crystal forms (Fig. 1a). Second, a few apatite grains occur at the margins of large FeNi metal grains within or outside of chondrules (Fig. 1b). Apatite is rarely included in FeNi metal, which usually contains diopside, olivine, chromite and merrillite as small inclusions. Third, many of the anhedral to euhedral apatite grains occur as isolated crystals in fine-grained matrix of $\mathrm{DaG}$ 978. The spatial distribution of some apatite grains in the matrix resembles a chain of beads (Fig. 1c). Regardless of the different textural occurrences, many of the apatite grains in DaG 978 are closely associated with anhedral to euhedral grains of high-Ca pyroxene and/or olivine (Fig. 1d). Some of the high-Ca pyroxene and olivine grains are included in coarse-grained apatite. Merrillite is common in FeNi metal, mainly, as inclusions. Most merrillite grains in $\mathrm{DaG} 978$ are $<20 \mu \mathrm{m}$ in size, only a few grains as large as $50 \mu \mathrm{m}$. No merrillite grains are observed within or around altered CAIs in DaG 978. Chemically, electron microprobe results reveal that apatite in $\mathrm{DaG} 978$ is highly $\mathrm{Cl}$ rich and has low concentrations of $\mathrm{F}$ and calculated $\mathrm{H}_{2} \mathrm{O}$ (Supplementary Table 1). Compared with apatite, merrillite always contains a few weight per cent of $\mathrm{MgO}, \mathrm{FeO}$ and $\mathrm{Na}_{2} \mathrm{O}$ (Supplementary Table 2 ). The high-Ca pyroxene closely associated with apatite contains low $\mathrm{Al}_{2} \mathrm{O}_{3}$ and $\mathrm{TiO}_{2}$, and high $\mathrm{FeO}$ and $\mathrm{Na}_{2} \mathrm{O}$ compared with primary high-Ca pyroxene in CAIs in DaG 978 (Supplementary Table 3, ref. 19).

REE and oxygen isotopic compositions. REEs of nine apatite grains and one merrillite grain from $\mathrm{DaG} 978$ are plotted in Fig. 2, comparing with those of $\mathrm{Ca}$-phosphate minerals from carbonaceous and ordinary chondrites $9,11,14$. The apatite grains in $\mathrm{DaG} 978$ all have identical REE patterns with positive $\mathrm{Eu}$ anomalies $\left(\mathrm{Eu} / \mathrm{Eu}^{*}=1.5-4.2\right.$; Fig. 2). The light REEs are enriched compared with the heavy REEs (La $\sim 26-62^{\star} \mathrm{CI}$; $\mathrm{Lu} \sim 3-12^{\star} \mathrm{CI}$; Supplementary Table 4). Merrillite contains higher REE concentrations than apatite. However, it also shows 

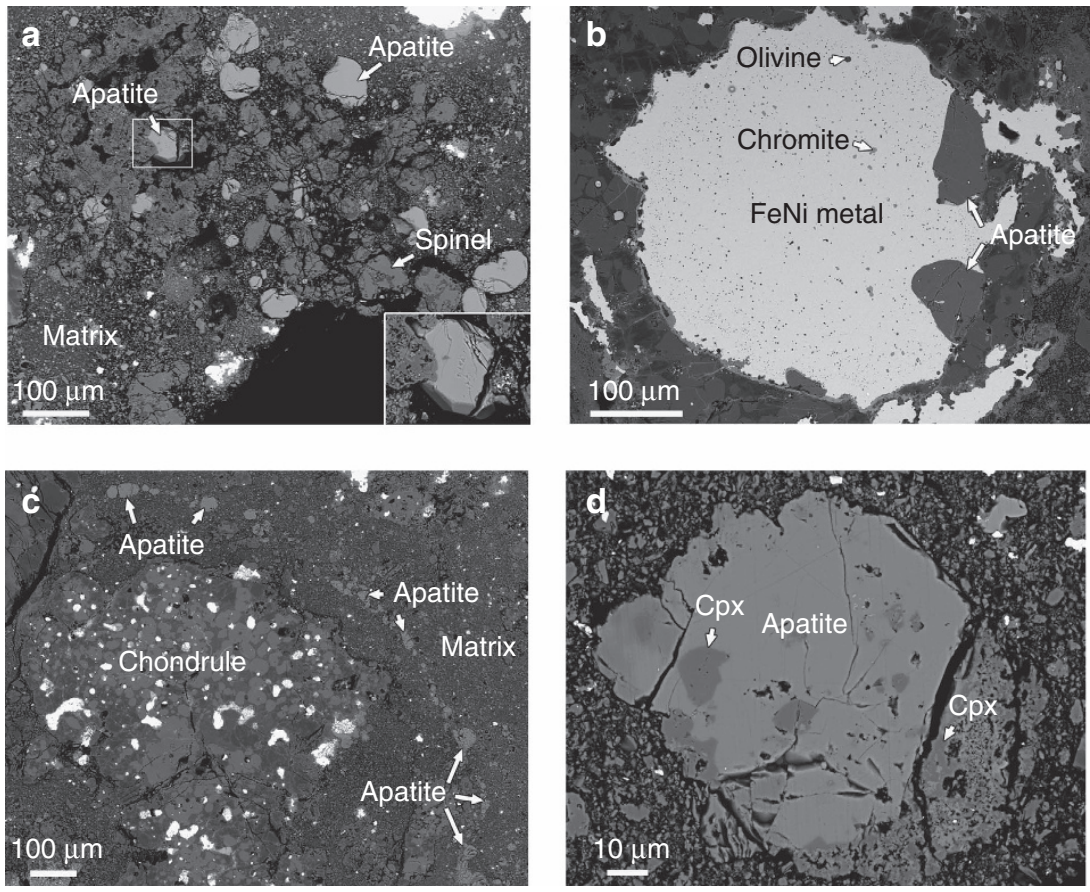

Figure 1 | Textural occurrences of apatite in DaG 978. (a) Backscattered electron image of apatite grains that are closely associated with a Ca,Al-rich inclusion. The apatite grain size varies from $\sim 10$ to $100 \mu \mathrm{m}$. Fine-grained anorthite has been partially altered to nepheline. The outline region contains a subhedral apatite grain with a well-developed crystal form. (b) Backscattered electron image of two apatite grains occurring at the margin of a large FeNi metal in a chondrule. The FeNi metal also contains fine-grained inclusions of chromite and olivine. (c) Backscattered electron image of apatite grains that resemble a chain of beads in matrix. (d) Backscattered electron image of a large apatite grain that is closely associated with high-Ca pyroxene (cpx).

The high-Ca pyroxene grains are anhedral to euhedral and vary from 3 to $15 \mu \mathrm{m}$ in size.

a weak, positive Eu anomaly (Fig. 2). Oxygen isotopic compositions of apatite, associated high-Ca pyroxene, olivine in refractory inclusions from $\mathrm{DaG} 978$ and that of bulk $\mathrm{DaG} 978$ (ref. 18) are plotted on a three-isotope oxygen diagram, $\delta^{17} \mathrm{O}$ versus $\delta^{18} \mathrm{O}$ (Supplementary Fig. 2). Oxygen isotopic compositions of both apatite and associated high-Ca pyroxene plot slightly below the terrestrial fractionation line. They have almost identical oxygen isotopic compositions with an average $\Delta^{17} \mathrm{O}$ value of $-1.5 \pm 3.2 \%$ ( 2 s.d.). The oxygen isotopic compositions are similar to those of anorthite and mesostasis in a sapphirine-bearing Al-rich chondrule from $\mathrm{DaG} 978$ (ref. 20), but distinctly different from those of refractory materials in $\mathrm{DaG} 978$ (Supplementary Fig. 2; Supplementary Table 5).

$\mathbf{U}-\mathbf{P b}$ ages of apatite formation. The SIMS measurements on 13 apatite grains reveal that apatite in $\mathrm{DaG} 978$ contains low concentrations of $U$ ( $0.075-0.178$ p.p.m. for most grains) and Th (0.002-0.096 p.p.m. for most grains; Supplementary Table 6). The $\mathrm{U} / \mathrm{Pb}$ and $\mathrm{Pb} / \mathrm{Pb}$ isotope ratios calculated by averaging the ratios of measurement counts are plotted on the ${ }^{204} \mathrm{~Pb} /$ ${ }^{206} \mathrm{~Pb}-{ }^{207} \mathrm{~Pb} /{ }^{206} \mathrm{~Pb}$ diagram and the ${ }^{207} \mathrm{~Pb} /{ }^{206} \mathrm{~Pb}-{ }^{238} \mathrm{U} /{ }^{206} \mathrm{~Pb}$ diagram (Fig. 3). The $\mathrm{Pb}$ isotope compositions of apatite in $\mathrm{DaG}$ 978 define a good ${ }^{204} \mathrm{~Pb} /{ }^{206} \mathrm{~Pb}-{ }^{207} \mathrm{~Pb} /{ }^{206} \mathrm{~Pb}$ isochron, giving a ${ }^{207} \mathrm{~Pb} /{ }^{206} \mathrm{~Pb}$ isochron age of $4,450 \pm 50 \mathrm{Myr}$ (2 s.d.) (Fig. $3 \mathrm{a}$ ). The three-dimensional linear regression on the ${ }^{207} \mathrm{~Pb} /{ }^{206}$ $\mathrm{Pb}-{ }^{238} \mathrm{U} /{ }^{206} \mathrm{~Pb}$ diagram gives a total $\mathrm{Pb} / \mathrm{U}$ isochron age of $4,448 \pm 110$ Myr (2 s.d.; Fig. 3b). The excellent consistence between the ${ }^{207} \mathrm{~Pb} /{ }^{206} \mathrm{~Pb}$ isochron age and the total $\mathrm{Pb} / \mathrm{U}$ isochron age indicates an age of apatite in $\mathrm{DaG} 978$ at $\sim 4,450$ Myr. Meanwhile, the common lead plane intercepts are at ${ }^{206} \mathrm{~Pb} /{ }^{204} \mathrm{~Pb}=15.9 \pm 1.5$ and ${ }^{207} \mathrm{~Pb} /{ }^{204} \mathrm{~Pb}=14.9 \pm 1.3$.

\section{Discussion}

The mineralogical features in $\mathrm{DaG} 978$ indicate that both metamorphic process and metasomatic process have affected this chondrite $^{19}$. The main evidence of metamorphism in DaG 978 is the chemical changes of some primary minerals (that is, olivine, chromite and FeNi metal) in chondrules and refractory inclusions. The chemical changes of primary minerals require thermally driven volume diffusion of some elements (that is, $\mathrm{Mg}, \mathrm{Fe}, \mathrm{Cr}$ and $\mathrm{Ni}$ ). The olivine-chromite thermometer suggests a maximum equilibrium temperature of $\sim 580-680^{\circ} \mathrm{C}$, indicating mild thermal metamorphism ${ }^{19}$. The real metamorphic temperature could be lower than this temperature, because the olivine-chromite pairs in a type 3.5 chondrite might not have reached chemical equilibrium ${ }^{21}$. On the other hand, lathshaped olivine, nepheline, Ca-phosphates and troilite in CAIs could not have formed with the metamorphic process alone. Instead, they could have formed during metamorphism in the presence of fluid (that is, replacement of primary minerals by fluids and/or direct precipitation from fluids ${ }^{19,22}$ ). For example, the formation of apatite that is closely associated with CAIs requires that $\mathrm{P}$ and $\mathrm{Cl}$ migrated from a source outside the CAIs. Without the presence of fluid, it is difficult to interpret the migration of these elements in DaG 978 (ref. 11). Lath-shaped olivine is widely interpreted as a product of fluid-assisted metamorphism $^{6,22}$. The lack of phyllosilicate minerals in $\mathrm{DaG}$ 978 indicates that the fluid-mineral interaction should have taken place at temperatures of $>200{ }^{\circ} \mathrm{C}$ (refs 4,6$)$. This requirement is generally consistent with the temperature deduced from the olivine-chromite geothermometry and those $\left(\sim 400^{\circ} \mathrm{C}\right.$ or higher) for other chondrites of around type 3.5 (refs 6,23). Therefore, the thermal event drove the diffusion of some elements in primary minerals. It might also result in the onset of fluid activity in DaG 978. During or intermediately subsequent to the 
a

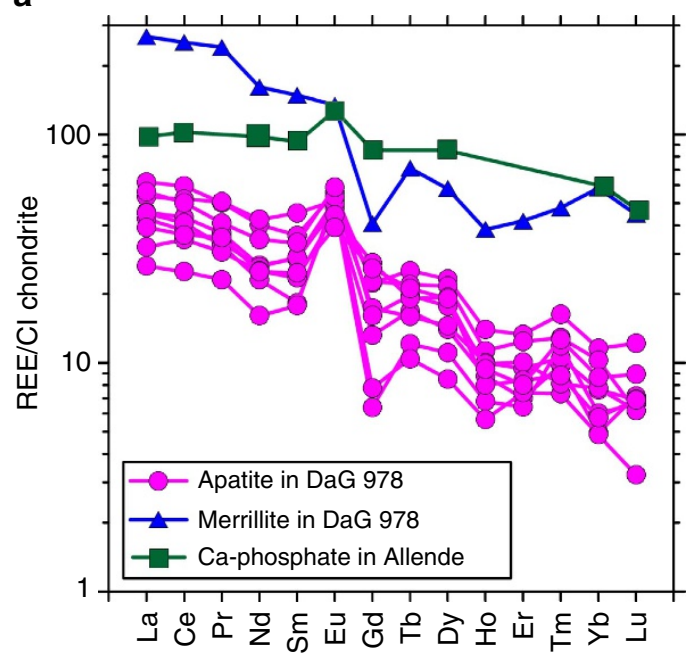

b

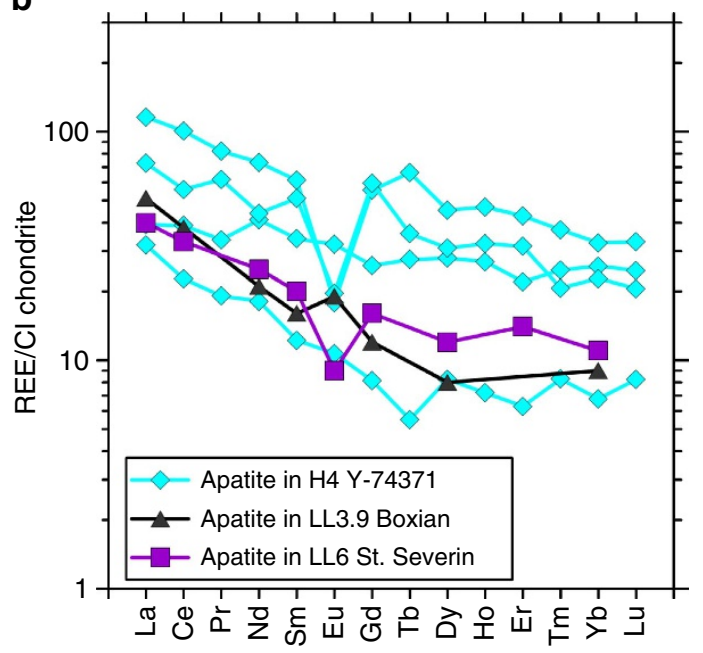

Figure 2 | Rare earth element patterns of Ca-phosphate minerals from different chondrites. (a) Apatite and merrillite in $\mathrm{DaG} 978$, and the Ca-phosphate in Allende have a positive Eu anomaly with heavy rare earth elements slightly depleted than light rare earth elements. (b) The rare earth element compositions in apatite in ordinary chondrites, which were determined by SIMS. Note that apatite grains in less equilibrated ordinary chondrites (H4 Yamato 74371 and LL3.9 Boxian) may contain weak, positive Eu anomalies. Data for Ca-phosphates in ordinary chondrites and Allende are from refs 9,11,14.

thermal event, the fluids interacted with the minerals in DaG 978 and formed the secondary minerals. In summary, the apatite in DaG 978 should be a product of fluid-assisted metamorphism on the parent body ${ }^{11}$.

Close textural association between apatite, and both FeNi metal and altered CAIs indicates that FeNi metal and CAIs could be the main sources of $\mathrm{P}$ and $\mathrm{Ca}$ for the formation of apatite in $\mathrm{DaG} 978$, respectively. Chondrule mesostasis could be another source of $\mathrm{P}$ because some mesostasis in primitive chondrites contain $\mathrm{P}_{2} \mathrm{O}_{5}$ up to $3.5 \mathrm{wt} \%$ (ref. 24). The source of Cl-rich fluid cannot be constrained based on the current observation. However, the partition coefficients of $\mathrm{F}$ and $\mathrm{OH}$ between apatite and aqueous fluids are much higher than that of $\mathrm{Cl}$ (ref. 25). Therefore, the low contents of $\mathrm{F}$ and calculated $\mathrm{H}_{2} \mathrm{O}$ in apatite from $\mathrm{DaG} 978$ indicate that the fluids from which apatite formed must be highly depleted in $\mathrm{F}$ and $\mathrm{H}_{2} \mathrm{O}$ and highly enriched in $\mathrm{Cl}$.
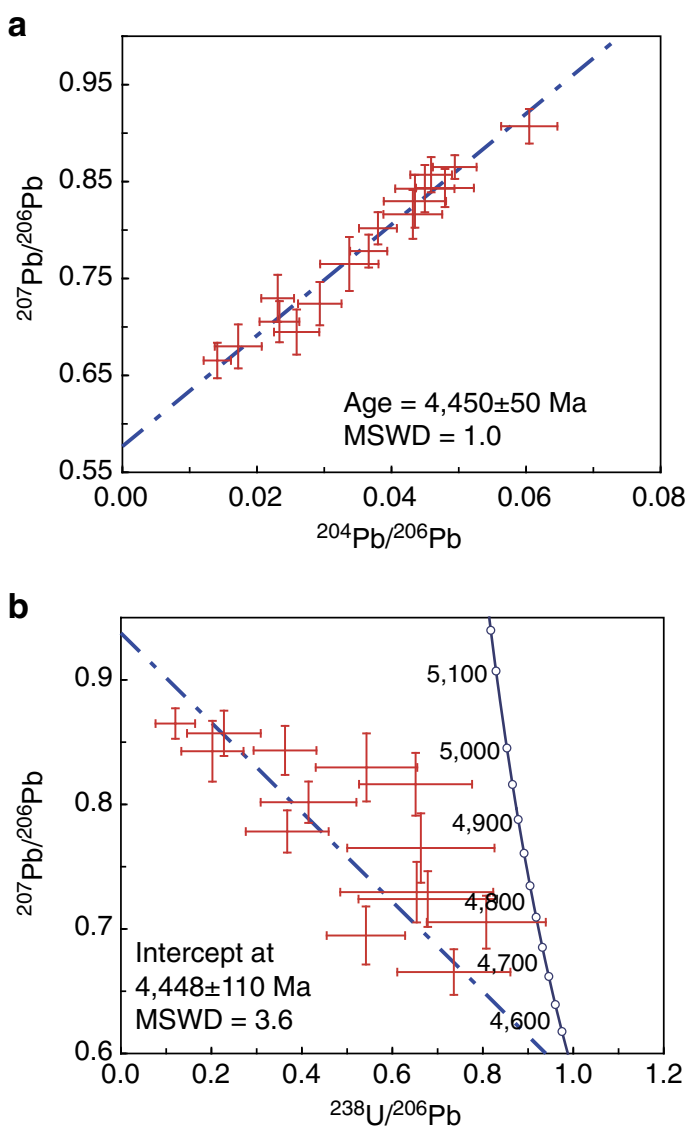

Figure 3 | The result of SIMS U-Pb dating of apatite in DaG 978.

(a) Inverse ${ }^{204} \mathrm{~Pb} /{ }^{206} \mathrm{~Pb}-{ }^{207} \mathrm{~Pb} /{ }^{206} \mathrm{~Pb}$ isochron diagram. (b) The projected diagram onto the ${ }^{238} \mathrm{U} /{ }^{206} \mathrm{~Pb}-{ }^{207} \mathrm{~Pb} /{ }^{206} \mathrm{~Pb}$ plane of the total $\mathrm{Pb} / \mathrm{U}$ isochron in the ${ }^{238} \mathrm{U} /{ }^{206} \mathrm{~Pb}-{ }^{207} \mathrm{~Pb} /{ }^{206} \mathrm{~Pb}-{ }^{204} \mathrm{~Pb} /{ }^{206} \mathrm{~Pb}$ three-dimension space. All data suggest that the crystallization age of apatite in DaG 978 is 4,450 Myr. The uncertainties for individual analyses are reported as 2 s.d. The ${ }^{207} \mathrm{~Pb} /{ }^{206} \mathrm{~Pb}$ isochron and total $\mathrm{Pb} / \mathrm{U}$ isochron ages were calculated at the $95 \%$ confidence level. MSWD, mean square of weighted deviated.

Although both the apatite in $\mathrm{DaG} 978$ and those in metamorphosed ordinary chondrites (OCs) could have formed though fluid-assisted metamorphism, their REE geochemistry and petrographic textures may reflect various contributions from metamorphic processes and metasomatic processes. Most of apatite grains in type 4-6 OCs exhibit negative Eu anomalies ${ }^{11,26}$. The negative Eu anomaly of the apatite from type 4-6 OCs could be a result of Eu equilibrium between apatite and recrystallized plagioclase during thermal metamorphism, with most Eu incorporated into plagioclase 9,11 . However, the apatite in $\mathrm{DaG}$ 978 has a positive Eu anomaly, similar to those observed in the Allende meteorite (type 3) and some of the apatite grains in type 3.9 and type $4 \mathrm{OCs}^{9,11,14}$. Such positive Eu anomalies indicate the lack of chemical equilibrium between apatite and plagioclase. Instead, they may reflect the chemical features of fluids from which apatite formed ${ }^{9}$. The petrographic textures of apatite in DaG 978 do support that fluid-mineral interaction should have played a key role for its formation. For example, fluid activity can well interpret the euhedral apatite crystals in matrix and those associated with CAIs. On the contrast, the apatite grains in highly metamorphosed OCs are mainly irregular in shape ${ }^{11}$. In addition, a pathway of fluid migration can best interpret the chain-like distribution of some apatite grains in matrix (Fig. 1c). In summary, the geochemical and petrographic features of 
apatite in $\mathrm{DaG} 978$ also reflect the onset of mild metamorphic process in the presence of an aqueous fluid in a type 3 chondrite parent body. Thus, the age of apatite records the timing of fluid activity in $\mathrm{DaG} 978$.

The ${ }^{207} \mathrm{~Pb} /{ }^{206} \mathrm{~Pb}$ isochron age $(4,450 \pm 50 \mathrm{Myr})$ of the apatite obtained in this study has two important implications. First, in the literature, all ages (short-lived isotope chronologies, Sr isotope composition and $\mathrm{Rb}-\mathrm{Sr}$ isotope chronology) about fluid activity in ESS are relative ages or model ages $7,27,28$. The apatite age obtained in this study is the first absolute age of fluid activity in ESS up to date. Second, the age of apatite in DaG 978 is 117 Myr younger than the oldest $\mathrm{CAI}^{29}$. This indicates that fluid activity may extend for a long time interval in ESS, from a few Myr to $\sim 117 \mathrm{Myr}$ after CAI formation. It has been suggested that the solar nebula has a lifetime of $\sim 10 \mathrm{Myr}$ (ref. 30). Therefore, the young age of the apatite in $\mathrm{DaG} 978$ demonstrates that this fluid activity must have taken place on the parent body ${ }^{7}$.

Decay of short-lived radionuclides and collisional heating has been proposed as significant heat sources to thermal metamorphism of $\mathrm{OCs}^{21}$. For example, the main heating source for fluid activity within $\sim 15 \mathrm{Myr}$ after CAI formation could be the decay of short-lived radionuclides (for example, ${ }^{26} \mathrm{Al}$ and ${ }^{60} \mathrm{Fe}$ (refs 7,31)). However, short-lived radionuclides cannot be a viable heat source for a thermal event that occurred $117 \mathrm{Myr}$ after CAI formation. Instead, collisional heating in late ESS may provide enough heat to activate the metamorphic event in the presence of fluid on the parent body of $\mathrm{DaG}$ 978. It has been suggested that there are frequent impact events at $4.47 \pm 0.03 \mathrm{Ga}$ in the main belt after the Moon-forming impact event, based on $\mathrm{Ar}-\mathrm{Ar}$ ages of ordinary chondrites ${ }^{32}$ and phosphate $\mathrm{U}-\mathrm{Pb}$ ages of ordinary chondrites ${ }^{16,17}$, and dynamic modelling ${ }^{33}$. On the basis of this excellent consistency between the apatite ${ }^{207} \mathrm{~Pb} /{ }^{206} \mathrm{~Pb}$ isochron age and the timing of impact events proposed in the literature, it is most likely that an impact event may have provided the heat to activate the metamorphic event at 4,450 Myr on the parent body of DaG 978 .

In addition, recent studies suggested that some large asteroids (that is, Ceres) have water evaporation from localized regions, indicating subsurface fluid activity ${ }^{34}$. Some of these water evaporation events could be related to impact events. Some of the evaporation events could be due to cryo-volcanism ${ }^{34}$. Thus, we cannot totally exclude the possibility that DaG 978 might have derived from the subsurface of a large asteroid, where fluid activity might have lasted up to 117 Myr after CAI formation.

In summary, the apatite in $\mathrm{DaG} 978$ has an origin by fluid-assisted metamorphism and was formed at 4,450 Myr, $\sim 117$ Myr later than CAI formation. Its age is the first absolute age about fluid activity in ESS. The late formation of apatite in DaG 978 represents a young metamorphic event in the presence of fluid in the parent body setting. An impact event at $\sim 4,450$ Myr may have provided the heat to activate this fluid activity in late ESS. Alternatively, this meteorite might be ejected from a large (possibly Ceres like) asteroid, where subsurface fluid activities could last up to $\sim 117 \mathrm{Myr}$ after CAI formation.

\footnotetext{
Methods

Petrography and major element analysis. Petrographic textures of apatite in DaG 978 were mainly observed with JEOL 7000F field-emission scanning electron microscope (SEM) at Hokkaido University and JEOL 6490 SEM at Nanjing University. Both SEM instruments are operated at an accelerating voltage of $15 \mathrm{kV}$. Mineral chemistry of apatite was determined using a JEOL 8100 electron probe micro-analyzer (EPMA) at Nanjing University. A defocused beam $(10 \mu \mathrm{m}$ in diameter) at a beam current of $10 \mathrm{nA}$ and an accelerating voltage of $15 \mathrm{kV}$ was used. A few natural and synthetic materials were used standards. All EPMA data are reduced with the ZAF (atomic number-absorption-fluorescence) correction procedure. Before EPMA analysis, all $\mathrm{Ca}$-phosphate minerals were qualitatively measured by energy dispersive spectrometers (EDS) installed on the SEM
}

instruments. Since SEM-EDS results show high chlorine and a very low intensity of fluorine, $\mathrm{Cl}$ and $\mathrm{F}$ are the first and second elements to be measured, respectively.

Oxygen isotope systematics. Oxygen isotope compositions of apatite and associated silicate minerals were determined with the Cameca IMS-1270 instrument at Hokkaido University. Before measurements, the polished sections of DaG 978 were carbon-coated. The primary ion beam was mass filtered positive $\mathrm{Cs}^{+}$ ions of $20 \mathrm{keV}$ and the beam spot size was $8-10 \mu \mathrm{m}$ in diameter. A primary beam current of $100 \mathrm{pA}$ was used to obtain a count rate of negative ${ }^{16} \mathrm{O}$ ions of $\sim 2 \times 10^{7}$ c.p.s. A normal-incident electron gun was used for charge compensation of the sputtered area. A mass resolving power of $\sim 5,500$ was used to separate ${ }^{17} \mathrm{O}$ from ${ }^{16} \mathrm{OH}$. Negative ${ }^{16} \mathrm{O}$ ions were detected with an axial Faraday cup, while negative ${ }^{17} \mathrm{O}$ and ${ }^{18} \mathrm{O}$ ions were detected with an axial electron multiplier detector, in magnetic peak-jumping mode. The instrumental mass fractionation effect was corrected using San Carlos olivine. The reported uncertainties of the individual analyses are expressed in 2 s.d., which were estimated by considering both the internal error of each measurement and the reproducibility of the standard measurements. After the measurements, all spots were evaluated using filed-emission SEM.

REE geochemistry. The REE compositions of apatite and merrillite were determined with the Cameca IMS-6f instrument at Hokkaido University. Before measurements, the polished sections of $\mathrm{DaG} 978$ were carbon-coated. The procedure was similar to that described in refs 35,36 . The primary beam was mass filtered ${ }^{16} \mathrm{O}^{-}$of $-14.5 \mathrm{keV}$ and irradiated on the sample surface to a diameter of $\sim 25 \mu \mathrm{m}$. The primary beam current is $10-15 \mathrm{nA}$. Kinetic energy filtering was used to reduce interferences from molecular ions by offsetting the sample acceleration voltage $(-100 \mathrm{eV})$. The energy bandwidth was $20 \mathrm{eV}$. The exit slit was set to a mass resolving power of $\sim 500$. Positive secondary ion intensities were counted for $10 \mathrm{~s}$ with an electron multiplier detector in magnetic peak-jumping mode. Each analysis included 15 cycles. Relative sensitivity factors between secondary ion intensity and concentration for each REE (relative to $\mathrm{Ca}$ ) were determined using the Takashima augite, for which REE contents have been well determined by instrumental neutron activation analysis ${ }^{37}$.

Uranium-lead isotopic systematics. The $\mathrm{U}-\mathrm{Pb}$ isotopic system of apatite was determined using the Cameca IMS-1280HR instrument at the Institute of Geology and Geophysics, Chinese Academy of Sciences, China, following the analytical procedure of refs 15,38. Before measurements, the polished sections of DaG 978 were carbon-coated. The $\mathrm{O}_{2}^{-}$primary beam was accelerated at $-13 \mathrm{kV}$, with an intensity of $\sim 10 \mathrm{nA}$. The ellipsoidal spot is $\sim 20 \times 30 \mu \mathrm{m}$ in size. The secondary ions were extracted at an initial energy of $10 \mathrm{keV}$. The entrance slit and field aperture were set to a mass resolution power of $\sim 8,000$. The energy slit was closed to a bandwidth of $60 \mathrm{eV}$ to reduce the energy dispersion. Detection of secondary ions took the advantage of both mono-collector mode and multi-collector mode. For each analysis in this study, secondary ion beam intensities of ${ }^{40} \mathrm{Ca}_{2}^{31} \mathrm{P}^{16} \mathrm{O}_{4}^{+}$, ${ }^{238} \mathrm{U}^{+}$and ${ }^{238} \mathrm{U}^{16} \mathrm{O}_{2}^{+}$were detected in L1-EM by peak-jumping sequences. In the second sequence, ${ }^{204} \mathrm{~Pb},{ }^{206} \mathrm{~Pb}$ and ${ }^{207} \mathrm{~Pb}$ were detected with multi-collector electron multipliers $\mathrm{L} 2, \mathrm{~L} 1$ and $\mathrm{C}$, respectively. In the third sequence, ${ }^{238} \mathrm{U}$, ${ }^{232} \mathrm{Th}^{16} \mathrm{O}$ and ${ }^{238} \mathrm{U}^{16} \mathrm{O}$ were measured with $\mathrm{L} 1, \mathrm{H} 1$ and $\mathrm{H} 2$, respectively. The $\mathrm{Pb} / \mathrm{U}$ ratios were calibrated with an empirical correlation between $\mathrm{Pb}+/ \mathrm{U}^{+}$ and $\mathrm{UO}^{2+} / \mathrm{U}^{+}$ratios, normalized to the 1,160 Myr apatite standard from the Prairie Lake alkaline-carbonatite complex in Ontario, Canada ${ }^{13,15}$. Each analysis included $10-20$ cycles. The $\mathrm{U} / \mathrm{Pb}$ and $\mathrm{Pb} / \mathrm{Pb}$ isotope ratios were calculated by averaging the ratios of measurement counts. Uncertainties for individual analyses are reported as 2 s.d. The ${ }^{207} \mathrm{~Pb} /{ }^{206} \mathrm{~Pb}$ isochron and total $\mathrm{Pb} / \mathrm{U}$ isochron ages were calculated at the $95 \%$ confidence level using the Isoplot/Ex 3.0 software $^{39}$.

Data availability. The data shown and discussed in this paper are presented in the Supplementary Information.

\section{References}

1. Brearley, A. J. \& Jones, R. H. in Planetary Materials. Vol. 36 (ed. Papike, J. J.) 3-1-3-398 (Mineralogical Society of America, 1998).

2. Scott, E. R. D. Chondrites and the protoplanetary disk. Ann. Rev. Earth Planet. Sci. 35, 577-620 (2007).

3. Brearley, A. J. in Treatise on Geochemistry. Vol. 1 (ed. Davis, A. M.) 247-268 (Elsevier, 2003).

4. Brearley, A. J. in Meteorites and the Early Solar System II. (eds Lauretta, D. S. \& McSween, Jr H. Y.) 587-624 (Arizona Univ. Press, 2006).

5. Zolensky, M. E., Krot, A. N. \& Benedix, G. Record of low-temperature alteration in asteroids. Rev. Mineral. Geochem. 68, 429-462 (2008).

6. Brearley, A. J. \& Krot, A. N. in Metasomatism and the Chemical Transformation of Rock. (eds Harlov, D. E. \& Austrheim, H.) 659-789 (Springer, 2013).

7. Krot, A. N. et al. in Meteorites and the Solar System II. (eds Lauretta, D. S. \& McSween, H. Y.) 525-553 (The Univ. of Arizona Press, 2006). 
8. Tyra, M. A., Brearley, A. J., Matzel, J. \& Hutcheon, I. D. in 41st Lunar and Planetary Science Conference (The Woodlands, Texas, 2010).

9. Ebihara, M. \& Honda, M. Rare earth elements in Ca-phosphates of Allende carbonaceous chondrite. Meteoritics 22, 179-190 (1987)

10. Göpel, C., Manhes, G. \& Allegre, C. J. U-Pb systematics of phosphates from equilibrated ordinary chondrites. Earth and Planetary Sci. Lett. 121, 153-171 (1994).

11. Jones, R. H. et al. Phosphate minerals in LL chondrites: A record of the action of fluids during metamorphism on ordinary chondrite parent bodies. Geochim. Cosmochim. Acta 132, 120-140 (2014).

12. Zhang, A. C. et al. P-O-rich sulfide phase in CM chondrites: constraints on its origin on the CM parent body. Meteoritics \& Planetary Sci. 51, 56-69 (2016).

13. Sano, Y., Oyama, T., Terada, K. \& Hidaka, H. Ion microprobe U-Pb dating of apatite. Chem. Geology 153, 249-258 (1999).

14. Terada, K. \& Sano, Y. Ion microprobe U-Pb dating and REE analyses of phosphates in H4-chondrite, Yamato-74371. Geophys. Res. Lett. 29, 98-1-98-4 (2002).

15. Li, Q. L. et al. In-situ SIMS U-Pb dating of phanerozoic apatite with low U and high common Pb. Gondwana Res. 21, 745-756 (2012).

16. Popova, O. P. et al. Chelyabinsk airburst, damage assessment, meteorite recovery, and characterization. Science 342, 1069-1073 (2013)

17. Yin, Q. Z. et al. Records of the Moon-forming impact and the $470 \mathrm{Ma}$ disruption of the $\mathrm{L}$ chondrite parent body in the asteroid belt from $\mathrm{U}-\mathrm{Pb}$ apatite ages of Novato (L6). Meteorit. Planet. Sci. 49, 1426-1439 (2014).

18. Choe, W. H., Huber, H., Rubin, A. E., Kallemeynm, G. W. \& Wasson, J. T. Compositions and taxonomy of 15 unusual carbonaceous chondrites. Meteorit. Planet. Sci. 45, 531-554 (2010).

19. Zhang, A. C. \& Yurimoto, H. Petrography and mineralogy of the ungrouped type 3 carbonaceous chondrite Dar al Gani 978. Meteorit. Planet. Sci. 48, 1651-1677 (2013).

20. Zhang, A. C., Itoh, S., Sakamoto, N., Wang, R. C. \& Yurimoto, H. Origins of Al-rich chondrules: Clues from a compound Al-rich chondrule in the Dar al Gani 978 carbonaceous chondrite. Geochim. Cosmochim. 130, 78-92 (2014).

21. Huss, G. R., Rubin, A. E. \& Grossman, J. N. in Meteorites and the Solar System II. (eds Lauretta, D. S. \& McSween, H. Y.) 567-586 (The Univ. of Arizona Press, 2006).

22. Krot, A. N., Petaev, M. I. \& Bland, P. A. Multiple formation mechanisms of ferrous olivine in $\mathrm{CV}$ carbonaceous chondrites during fluid-assisted metamorphism. Antarct. Meteorite Res. 17, 153-171 (2004).

23. Jones, R. H. \& Rubie, D. C. Thermal histories of CO3 chondrites: application of olivine diffusion modelling to parent body metamorphism. Earth Planet. Sci. Lett. 106, 73-86 (1993).

24. Jones, R. H. Petrology and mineralogy of type II, FeO-rich chondrules in Semarkona (LL3.0): Origin by closed-system fractional crystallization, with evidence for supercooling. Geochim. Cosmochim. Acta 54, 1785-1802 (1990).

25. Kusebauch, C., John, T., Whitehouse, M. J., Klemme, S. \& Putnis, A Distribution of halogens between fluid and apatite during fluid-mediated replacement processes. Geochim. Cosmochim. Acta 170, 225-246 (2015).

26. Crozaz, G. \& Zinner, E. Ion probe determinations of the rare earth concentrations of individual meteoritic phosphate grains. Earth Planet. Sci. Lett. 73, 41-52 (1985).

27. Macdougall, J. D., Lugmair, G. W. \& Kerridge, J. F. Early solar system aqueous activity: $\mathrm{Sr}$ isotope evidence from the Orgueil CI meteorite. Science 307, 249-251 (1984).

28. Zolensky, M. E. et al. Asteroidal water within fluid inclusion-bearing halite in an H5 chondrite, Monahans. Science 185, 1377-1379 (1998).

29. Amelin, Y., Krot, A. N., Hutcheon, I. D. \& Ulyanov, A. A. Lead isotopic ages of chondrules and calcium-aluminum-rich inclusions. Science 297, 1678-1683 (2002).

30. Muzerolle, J., Allen, L. E., Megeath, S. T., Hernández, J. \& Gutermuth, R. A. A. A spritzer census of transitional protoplanetary disks with AU-scale inner holes. Astrophys. J. 708, 1107-1118 (2010).
31. Cohen, B. A. \& Cokerm, R. A. Modeling of liquid water on CM meteorite parent bodies and implications for amino acid racemizations. Icarus 145, 369-381 (2000).

32. Swindle, T. D., Kring, D. A. \& Wierich, J. R. ${ }^{40} \mathrm{Ar}-{ }^{39} \mathrm{Ar}$ ages of impacts involving ordinary chondrite meteorites. Geol. Soc. Lond. Spec. Publ. 378, 333-347 (2014).

33. Bottke, W. F. et al. Dating the Moon-forming impact event with asteroidal meteorites. Science 348, 321-323 (2015).

34. Küppers, M. et al. Localized sources of water vapour on the dwarf planet (1) Ceres. Nature 505, 525-527 (2014).

35. Yurimoto, H., Yamashita, A., Nishida, N. \& Sueno, S. Quantitative SIMS analysis of GSJ rock reference samples. Geochem. J. 23, 215-236 (1989).

36. Wang, W. Y. \& Yurimoto, H. Analysis of rare earth elements in garnet by SIMS. Ann. Rep. Inst. Geosci. Univ. Tsukuba 19, 87-91 (1993).

37. Onuma, N., Higuchi, H., Wakita, H. \& Nagasawa, H. Trace element partition between 2 pyroxenes and host lava. Earth Planet. Sci. Lett. 5, 47-51 (1968).

38. Liu, Y. et al. Towards higher precision SIMS U-Pb zircon geochronology via dynamic multi-collector analysis. J. Anal. At. Spectrom. 30, 979-985 (2015).

39. Ludwig, K. R. User's manual for Isoplot, V. 3.0, a geochronological toolkit for Microsoft Excel. Berkeley Geochronological Center, Special Publication 4 (2003).

\section{Acknowledgements}

This work was funded by grants from Natural Science Foundation of China (41373065), the State Key Laboratory for Mineral Deposits Research at Nanjing University (ZZKT-201322) and the Fundamental Research Funds for the Central Universities.

\section{Author contributions}

A.C.Z. designed and initialized the research, and wrote the paper. Q.L.L. contributed to the U-Pb dating analysis. H.Y. is the director of Isotope Imaging Laboratory at Hokkaido University, Japan, and contributed to the interpretation of apatite origin and ages. N.S set up the SIMS instruments for REE and oxygen isotope measurements. X.H.L. is the director of the SIMS laboratory at Institute of Geology and Geophysics, Chinese Acad emy of Sciences, China. S.H., Y.T.L. and R.C.W. contributed to the interpretation of apatite origin. All authors contributed to preparation of the manuscript.

\section{Additional information}

Supplementary Information accompanies this paper at http://www.nature.com/ naturecommunications

Competing financial interests: The authors declare no competing financial interests.

Reprints and permission information is available online at http://npg.nature.com/ reprintsandpermissions/

How to cite this article: Zhang, A-C. et al. Young asteroidal fluid activity revealed by absolute age from apatite in carbonaceous chondrite. Nat. Commun. 7:12844 doi: $10.1038 /$ ncomms12844 (2016)

This work is licensed under a Creative Commons Attribution 4.0 International License. The images or other third party material in this article are included in the article's Creative Commons license, unless indicated otherwise in the credit line; if the material is not included under the Creative Commons license, users will need to obtain permission from the license holder to reproduce the material To view a copy of this license, visit http://creativecommons.org/licenses/by/4.0/

(C) The Author(s) 2016 